\title{
SIMPLIFIED SEISMIC LOSS FUNCTIONS FOR SUSPENDED CEILINGS AND DRYWALL PARTITIONS
}

\author{
Rajesh P. Dhakal ${ }^{1}$, Atefeh Pourali ${ }^{2}$ and Sandip K. Saha ${ }^{3}$
}

(Submitted June 2015; Reviewed December 2015; Accepted January 2016)

\begin{abstract}
Post-disaster reconnaissance reports frequently list non-structural components (NSCs) as a major source of financial loss in earthquakes. Moreover, minimizing their damage is also of vital significance to the uninterrupted functionality of a building. For efficient decision making, it is important to be able to estimate the cost and downtime associated with the repair of the damage likely to be caused at different hazard levels used in seismic design. Generalized loss functions for two important NSCs commonly used in New Zealand, namely suspended ceilings and drywall partitions are developed in this study. The methodology to develop the loss functions, in the form of engineering demand parameter vs. expected loss due to the considered components, is based on the existing framework for the storey level loss estimation. Nevertheless, exhaustive construction/field data are employed to make these loss functions more generic. In order to estimate financial losses resulting from the failure of suspended ceilings, generalized ceiling fragility functions are developed and combined with the cost functions, which give the loss associated with typical ceilings at various peak acceleration demands. Similarly, probabilities of different damage states in drywall partitions are combined with their associated repair/replacement costs to find the cumulative distribution of the expected loss due to partitions at various drift levels, which is then normalized in terms of the total building cost. Efficiencies of the developed loss functions are investigated through detailed loss assessment of case study reinforced concrete (RC) buildings. It is observed that the difference between the expected losses for ceilings, predicted by the developed generic loss function, and the losses obtained from the detailed loss estimation method is within $5 \%$. Similarly, the developed generic loss function for partitions is able to estimate the partition losses within $2 \%$ of that from the detailed loss assessment. The results confirm the accuracy of the proposed generic seismic loss functions.
\end{abstract}

\section{INTRODUCTION}

Non-structural components (NSCs) make up a considerable proportion of the total building cost [1], often outweighing the cost of structural components in most building uses. Moreover, performance of NSCs (and contents/services) is crucial for the continuous operation of the building. Even at small to moderate levels of ground shaking, where no noticeable structural damage occurs, damage to non-structural components (such as acoustic ceilings) and services can cause a substantial downtime resulting in a significant loss of income. Examples of damage caused to suspended ceilings and partition walls during past earthquakes are shown in Figures 1(a) and 1(b), respectively. Studies have shown that damage to non-structural components such as drywall partitions and acoustic ceilings (as well as generic
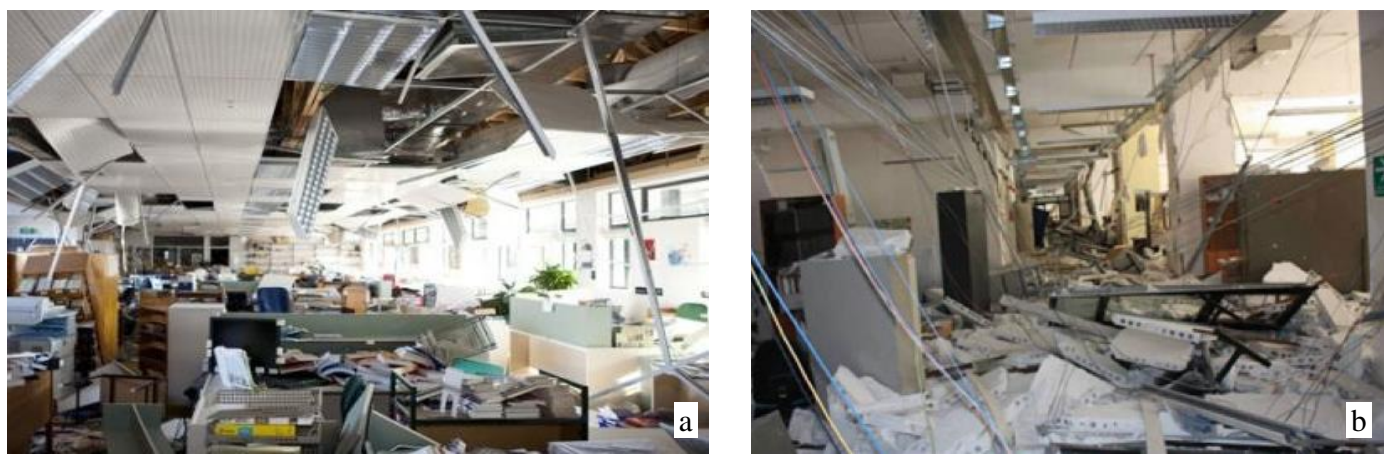

Figure 1: (a) Collapsed suspended ceilings and (b) gypsum block partitions [2]. components) comprise a significant proportion of the total loss in moderate earthquakes where no structural collapse occurs, and loss due to structural damage contributes little to the total loss [3]. The weeks-long closure of the modern BNZ building in Wellington, New Zealand, primarily due to ceiling damage during the $M_{w} 6.5$ Seddon earthquake on 16 August 2013 is a recent example. Recent earthquakes in New Zealand have directed the attention of engineers, policy makers and insurance companies toward NSCs and their significant contribution to the overall financial loss caused by such disasters, and significant progress has been made lately in understanding and improving seismic performance of NSCs [4]. 
Estimation of loss in buildings has been a topic of interest since the early 1930s. Freeman [5] in one of the earliest studies of loss estimation, provided rough estimates of probable average earthquake loss ratios for different localities and building types to be employed by insurance industry. Scholl [6] introduced a deterministic component-based loss estimation methodology to improve prediction of loss in highrise buildings. He defined damage to various structural and non-structural components as a percentage of component replacement cost. This damage was estimated using motiondamage functions previously developed for high-rise buildings. Steinburgge [7] proposed a methodology that linked ground motion intensity to percentage loss for different classes of construction. Monte Carlo (MC) simulation was employed by Singhal and Kiremidjian [8] to account for various uncertainties including ground motion, estimation of damage and repair cost in predicting loss. Application of quantitative measures of ground shaking in estimation of loss was developed in 1997 through the introduction of HAZUS ${ }^{\circledR}$ to reduce the uncertainties associated with the seismic hazard [9].

Considering the enormous need of the present day, significant advancement has been made in the seismic loss estimation framework during the last decade [10-11]. Probabilistic loss estimation methodology for providing quantitative measures of seismic performance in terms of the economic losses are reported by several researchers [3, 12-15]. Loss disaggregation proposed in earlier studies provides a way to identify the ground motion intensities, levels of structural response and structural and non-structural components that primarily contribute to damage and direct economic losses. The results of the disaggregation of the economic losses estimated for a case study reinforced concrete (RC) building showed that the majority of economic losses are from NSCs. Recently, several research projects have been conducted on seismic loss estimation of buildings incorporating the effect of NSCs according to the FEMA P-58 [16] methodology. More recently, Cutfield et al. [17] used this methodology for life cycle analysis of base-isolated buildings.

It is gradually being accepted in the earthquake engineering community that the current seismic design approach, which aims for serviceability in small earthquakes and life safety in moderate/large earthquakes is not enough to meet stakeholders' expectation. In future versions of performance based seismic design, minimization of seismic losses from different sources (i.e., damage, downtime and injury) must be added as a key objective. A concept of a similar seismic design approach, called Loss Optimisation Seismic Design (LOSD) was discussed earlier by Dhakal [18]. For such a lossbased seismic design approach, designers need to estimate the likely building loss associated with structural and nonstructural components (including damage repair and downtime) at ground motion intensities corresponding to different design limit states.

Depending on the nature and extent of damage incurred, NSCs require different levels of repair ranging from minor repair to complete replacement, which are both costly and time consuming. The downtime associated with this kind of damage can impose a considerable financial burden on a property that is otherwise structurally sound. Therefore, it is advisable to consider non-structural damage in the early stages of decision making. The current state-of-the-art in terms of seismic loss estimation requires detailed component-based modelling and a series of probabilistic computations. Although some computer based tools, such as SLAT [19] and PACT [16] do exist, their use still requires significant expert knowledge, and is not hence conducive for everyday use by design engineers. Ramirez and Miranda [15] proposed to develop floor level generalized loss function for quick estimation of seismic loss for typical building categories. They combined the distributions of several components for a typical building category instead of actual quantities of the components to develop engineering demand parameter $(E D P)$ vs. expected loss functions. After combining the expected loss of all the probable components at a floor level, generalized floor level loss functions were proposed. Later, Farokhnia and Porter [20] proposed a procedure for estimating the mean nonstructural vulnerability of a building category. The procedure takes structural properties, such as floor area and structural system, the quantity of the top five or so most cost intensive NSCs and the total non-structural construction cost of the building. However, the procedure is effectively applicable only when the detailed component inventory is available to the assessing engineer, which may not be feasible at the early design stage. Therefore, probabilistic generalized relationships for different structural and non-structural components need to be developed for estimating the expected losses at given EDP level.

The primary aim of this work is to develop EDP vs. generalized expected loss functions for the suspended ceilings and drywall partitions used in typical RC office buildings in New Zealand. Herein, the loss functions are developed in line with the methodology proposed by Ramirez and Miranda [15]. However, the component distributions are generated using extensive data collected from various office buildings in Christchurch, New Zealand. Furthermore, the generalized loss functions are normalized in terms of the total building cost. The normalized generic seismic loss functions, developed herein for the suspended ceilings and drywall partitions, can readily be used to estimate likely losses due to these components at different levels of EDP in typical RC office buildings in New Zealand. Major objectives of this work are: (i) to generate component distributions of suspended ceilings and drywall partitions based on data collected from typical office buildings in Christchurch, New Zealand, and (ii) to use these component distributions along with the cost information in developing the generalized loss functions for rapid estimation of expected seismic losses contributed by the suspended ceilings and drywall partitions.

\section{METHODOLOGY}

For loss-based design, designers need to estimate likely losses from different building components at different limit states; so that the component losses can be assembled to estimate the total building loss and compared with tolerable loss limits. In probabilistic calculation, probable loss is contributed by the prospect of total building "collapse", and the building not collapsing but sustaining different extent of "damage" to different components. As life safety and collapse prevention are the core aims of seismic design, the probability of building collapse at the limit states used in design is extremely low (if not nil), therefore can be justifiably ignored. The present day seismic loss estimation methodologies are primarily based on the framework developed at the Pacific Earthquake Engineering Research (PEER) centre and the details can be found elsewhere $[10-12,21]$. Here, the relationships pertinent to the objectives of the present study are discussed.

At a given limit state, the likely seismic loss from a component for a given building is the product of three quantities: (i) the likely engineering demand parametre (EDP) at the limit state, (ii) likely extent of damage at the limit state $E D P$ and (iii) likely cost to repair the damage (or to replace the irreparably damaged component). The above statement only provides a simple conceptual representation of a complex probabilistic problem. If a deterministic relationship existed among the seismic intensity, $E D P$, damage and repair cost, the above statement could be readily used to calculate the component loss needed for loss-based decision making. Nevertheless, uncertainties invariably exist in all 
interrelationships making the process more complex. Some $E D P$ s take different forms depending on the component under consideration and the damage needs to be evaluated in terms of a number of discrete milestones.

The most uncertain/vague among the three interrelationships is the first; i.e. between the $E D P$ and the limit state. For this discussion, let us keep aside the unavoidable record-to-record randomness among different ground motions scaled to the same intensity corresponding to the limit state. Even for a single ground motion, the EDP (peak inter-storey drift ratio $(I D R)$ or peak floor acceleration $(P F A)$ ) varies between different buildings and even for the same building between different floors/storeys. Hence, it is extremely difficult (if not impossible) to generalise the $E D P$-limit state relationship for non-structural components. Consequently, in this study generic loss functions are derived for a wide range of values of $E D P$. The functions can readily be applied for any combination of limit state and floor/storey hosting the component. However, note that the corresponding EDP will have to be assessed separately beforehand through structural analysis. Herein, the expected EDPs are computed based on the simplified procedure stipulated in the New Zealand Standard [22]. However, more refined approaches (e.g. [2324]) can be followed, or detailed non-linear dynamic analysis can be performed to obtain the EDPs for the considered building at a given site.

Moreover, the repair/replacement costs of most non-structural components are quoted per unit area/number. Hence, the derived cost will have to be multiplied by the total area/number of the component in the floor/storey of the building under consideration. Despite the scope of the functions developed here being limited to RC buildings used as offices, the density of non-structural components such as ceilings and partitions can vary widely in such buildings. To account for this variation and the inherent uncertainties in other relationships, ideally a series of integrations using probabilistic interrelationships between different variables, such as those used in seismic risk assessment methodologies [14], should be conducted. Although in this study, deterministic calculations are used to develop the loss functions, the uncertainties are accounted for, and propagated through to the final step using MC simulation by coding a program in MATLAB ${ }^{\circledR}$.

To generate the input values for MC simulation, the variations need to be quantified in advance are: (i) variation of the component amount per square metre of building plan, (ii) variation of damage for a given $E D P$, and (iii) variation of the repair costs for different damage categories. The second variation comes from the fragility functions, which are well researched, and can be found in literature for most of the components. For quantifying the other two variations, two sets of data were collected for each component, i.e. suspended ceilings and drywall partitions. These data sets include: (i) distribution of these two components in typical RC office buildings, and (ii) costs required to repair different categories of damage to these components. These data were statistically fitted to suitable probability distributions. The input parameters for the MC simulations were generated randomly based on the assigned probability distribution functions.

Expected loss due to a component at a floor level for a given value of $E D P\left(L_{c / E D P}\right)$ can be calculated deterministically as $[2,15]$,
$L_{c / E D P}=A_{c} \times \sum_{i=1}^{n_{D S}} P\left(D_{i} \mid E D P\right) \times l_{c / D_{i}}$

where $A_{c}$ is the total area/number of the component in the floor; $l_{c / D_{i}}$ is the repair cost per unit area of the component for the damage state $D_{i} ; n_{D S}$ is the number of discrete damage states considered in the component fragility; and $P\left(D_{i} \mid E D P\right)$ is the probability of damage being in the $i^{\text {th }}$ damage state for the given $E D P$ value (say $e d p$ ). Here, $l_{c / D_{i}}$ are generated using the assigned probability distributions based on the collected data, whereas $P\left(D_{i} \mid E D P\right)$ can be computed from the fragility functions as,

$$
\begin{aligned}
P\left(D_{i} \mid E D P=e d p\right)= & \Phi\left(\ln \left(\frac{e d p}{\theta_{i}}\right) / \beta_{i}\right)-\Phi\left(\ln \left(\frac{e d p}{\theta_{i+1}}\right) / \beta_{i+1}\right) \\
& \text { for } 0<i<n_{D S}
\end{aligned}
$$

and

$$
\begin{gathered}
P\left(D_{i} \mid E D P=e d p\right)=\Phi\left(\ln \left(\frac{e d p}{\theta_{i}}\right) / \beta_{i}\right) \\
\text { for } i=n_{D S}
\end{gathered}
$$

where, $\theta_{i}$ and $\beta_{i}$ are the median and logarithmic standard deviation of the capacity to resist its $i^{\text {th }}$ damage state, respectively; and $\Phi()$ is the standard normal cumulative distribution function.

For a given $E D P$, this calculation is repeated with different randomly generated values of the inputs. The losses calculated from the large number of MC simulations are then interpreted probabilistically to obtain the mean and standard deviation. This process is repeated for different values of $E D P$; and finally the expected component loss (mean as well as the upper and lower bound) functions are generated in the form of loss vs. EDP plots. In order to test and confirm the accuracy and feasibility of the proposed loss functions, data obtained from some existing buildings are used as case studies.

Component distribution data is collected from RC office buildings located primarily within Christchurch Central Business District (CBD). Note that the distributions of NSCs (ceilings, partitions, etc.) obviously depend on the room sizes, which are primarily influenced by the use of the buildings. Hence, the outcome of this work may not strictly apply to buildings used for other purposes, which require distinctly different room sizes. Although the component distribution data was taken from buildings in Christchurch, they should be representative of similar buildings throughout New Zealand, as the practice within the country does not vary widely. It is assumed that enough data samples were collected to capture the variability/uncertainty. The cost data were taken from different sources (builders, contractors, suppliers and manufacturers) serving the whole country; so there should not be any bias induced by the temporary demand surge in Christchurch following the recent Canterbury earthquakes. The following two sections describe the data collections for component distribution generation, development of normalized generic loss functions and case studies for suspended ceiling and drywall partitions, respectively. 

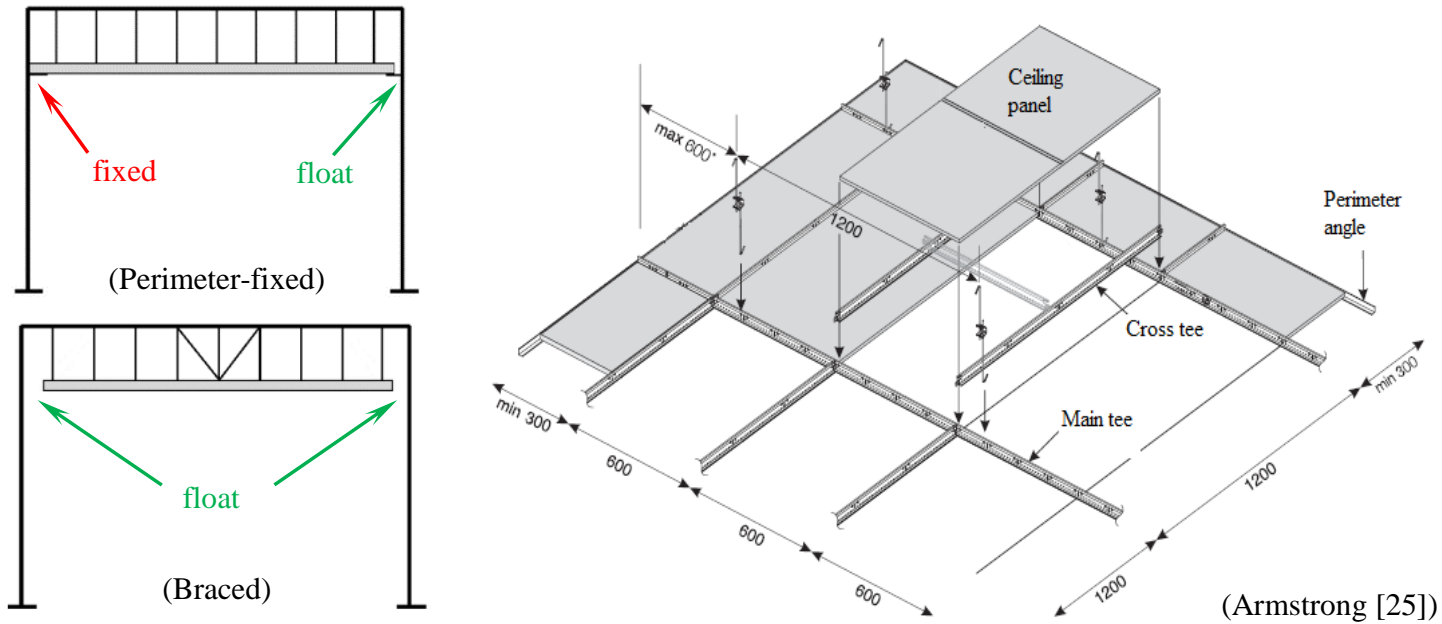

Figure 2: Schematic diagram and details of suspended ceiling.

\section{SECTION I: SUSPENDED CEILINGS}

Suspended ceilings are non-structural or architectural components that serve various purposes in a building. They provide a clean, pleasant overhead finish surface that hides services, pipes, ductwork etc. They are also effective in sound absorption and fire protection besides adding aesthetic character to the space. Suspended ceilings used in New Zealand typically consist of inverted $\mathrm{T}$-shaped galvanized steel beams that form $1200 \mathrm{~mm} \times 600 \mathrm{~mm}$ or $600 \mathrm{~mm} \times 600$ $\mathrm{mm}$ modules to support ceiling panels (Figure 2). The suspension system is supported by the structure above via either vertical steel hanger wires or braces. On the perimetres, the ceiling is either fixed to the structure via rivets and clips or free to slide on perimetre angles. These ceilings are very common in commercial buildings and they suffered extensive damage during the 2010 - 2011 Canterbury earthquakes [2628]. Damage to the ceilings can be the result of components reaching their load carrying capacity. For example, end-fixing rivets can yield in shear or can be pulled out due to large axial force, and grid connections can break under tension. This damage is the result of the inertial force induced in grid members by the floor acceleration.

\section{Distribution of Suspended Ceilings in Office Areas}

Ceiling size refers to the total area of the ceiling continually connected through grid elements. Therefore, the assumption can be made that the ceiling size is equal to the size of the room. This assumption implies that the distribution of room sizes provides the distribution of ceiling sizes. However, for rooms of significantly large dimension, the ceiling systems were found to be bounded and separated by structural components, such as intermediate beams. In that case, the ceiling area was considered equal to the smallest area enclosed by structural members. For this purpose, both architectural and structural drawings of a large number of Christchurch buildings damaged in the 2010-2011 Canterbury earthquakes were accessed. A library of drawings corresponding to 725 rooms from 29 different office buildings located in Christchurch CBD was collected. The number of stories in the buildings under consideration varied from 1 to 13 . Nevertheless, detail drawings corresponding to all floor levels of a building and all rooms at a particular floor level were not available. Therefore, no discriminations were made in the collected data regarding the floor level or number of stories in the building. Only clearly distinguishable floor areas were measured, and ratios between the long side and shorter side (room aspect ratio) were noted. In total, 606 data corresponding to the ceiling area and 542 data corresponding to the room aspect ratio were recovered for the present study. The difference between the sizes of these two datasets represents the number of rooms subdivided by intermediate beams resulting in multiple ceiling areas for a single room.

The histogram and the cumulative probability distribution of the observed ceiling areas are presented in Figures 3(a) and 3(b), respectively. Two theoretical cumulative distribution functions (CDFs), normal and lognormal, are also presented in Figure 3(b). The observed data are fitted with normal distributions $\left(\right.$ mean $=34.92 \mathrm{~m}^{2}$, standard deviation $=19.82$ $\mathrm{m}^{2}$ ) and lognormal distributions (median $=30 \mathrm{~m}^{2}$, logarithmic standard deviation $=0.57 \mathrm{~m}^{2}$ ). To compare the appropriateness of the theoretical distribution functions, two different goodness-of-fit (GOF), Chi square $\left(\chi^{2}\right)$ and KolmogorovSmirnov (K-S) tests are carried out. The $\chi^{2}$ statistics ( $p$ value) and K-S statistic $\left(D_{n, \max }\right)$ are reported in the figure for comparison. Lognormal distribution is found to fit better to the observed ceiling areas.

It is observed from Figure 3 that only about $25 \%$ of the rooms have an area of less than $20 \mathrm{~m}^{2}$. The relatively large proportion of bigger rooms in this distribution is due to the fact that it is common in New Zealand to have large halls divided into staff compartments using half-height board partitions where the ceilings span over the whole length of the hall. It is noted that majority of the rooms in buildings are rectangular; hence, the ceiling grid members spanning along the longer dimension of the room are subjected to greater forces, and the longer side of the ceiling is the critical direction if a ceiling is subjected to similar accelerations in both directions. Consequently, in addition to the distribution of ceilings area, distribution of the longer side length of ceilings is also required. For this purpose, aspect ratios of the studied rooms were also measured. It is assumed in this study that the room aspect ratio represents the ceiling aspect ratio. The histogram and the cumulative probability distribution of the observed room aspect ratios are presented in Figures 4(a) and 4(b), respectively. Two theoretical CDFs, normal and lognormal, are also presented in Figure 4(b). From the GOF tests it is observed that the room aspect ratios are better represented by the lognormal distribution (median $=1.38$ and logarithmic standard deviation $=0.204)$ as compared to the normal distribution (mean $=1.44$ and standard deviation $=0.307$ )

Having the ceiling area $(A)$ and the room aspect ratio $(r)$, the longer side $\left(L_{L}\right)$ length is obtained as,

$L_{L}=\sqrt{A \times r}$ 

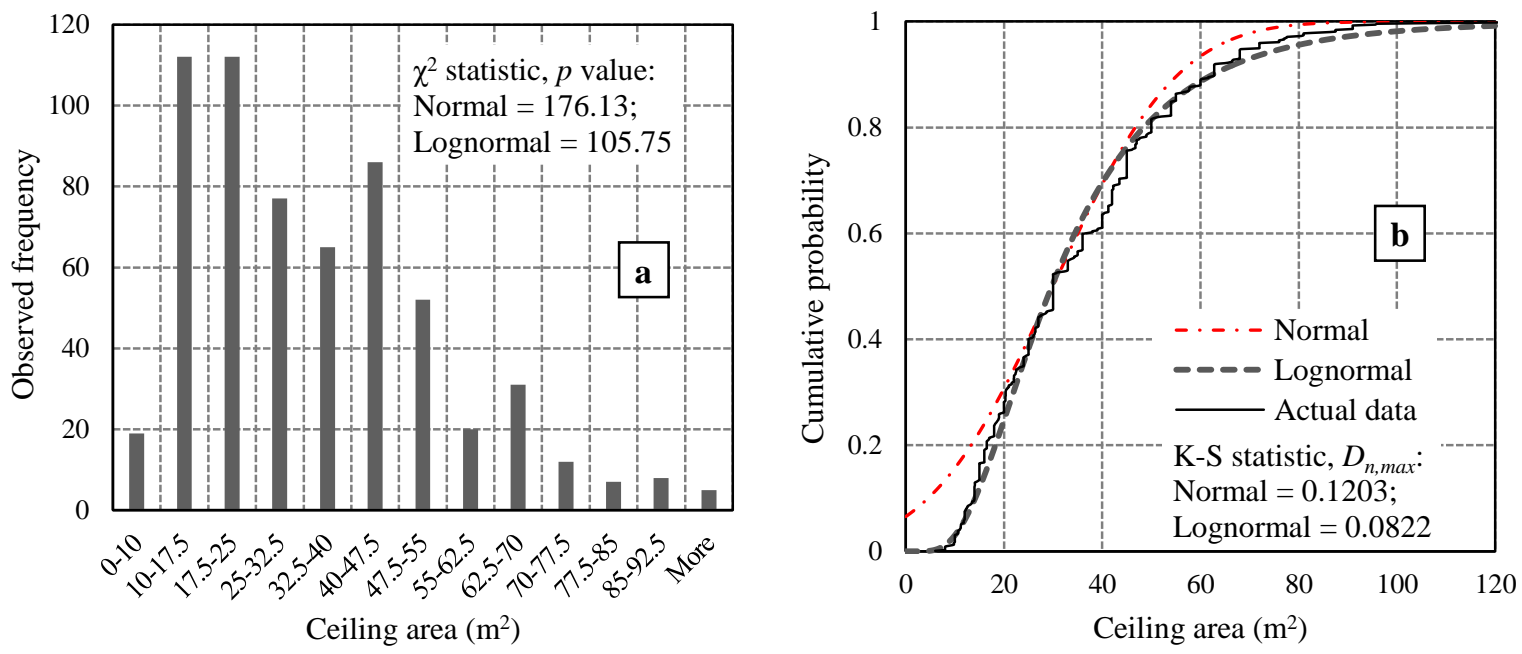

Figure 3: (a) Histogram of collected data; and (b) fitted cumulative distribution functions for ceiling a reas.
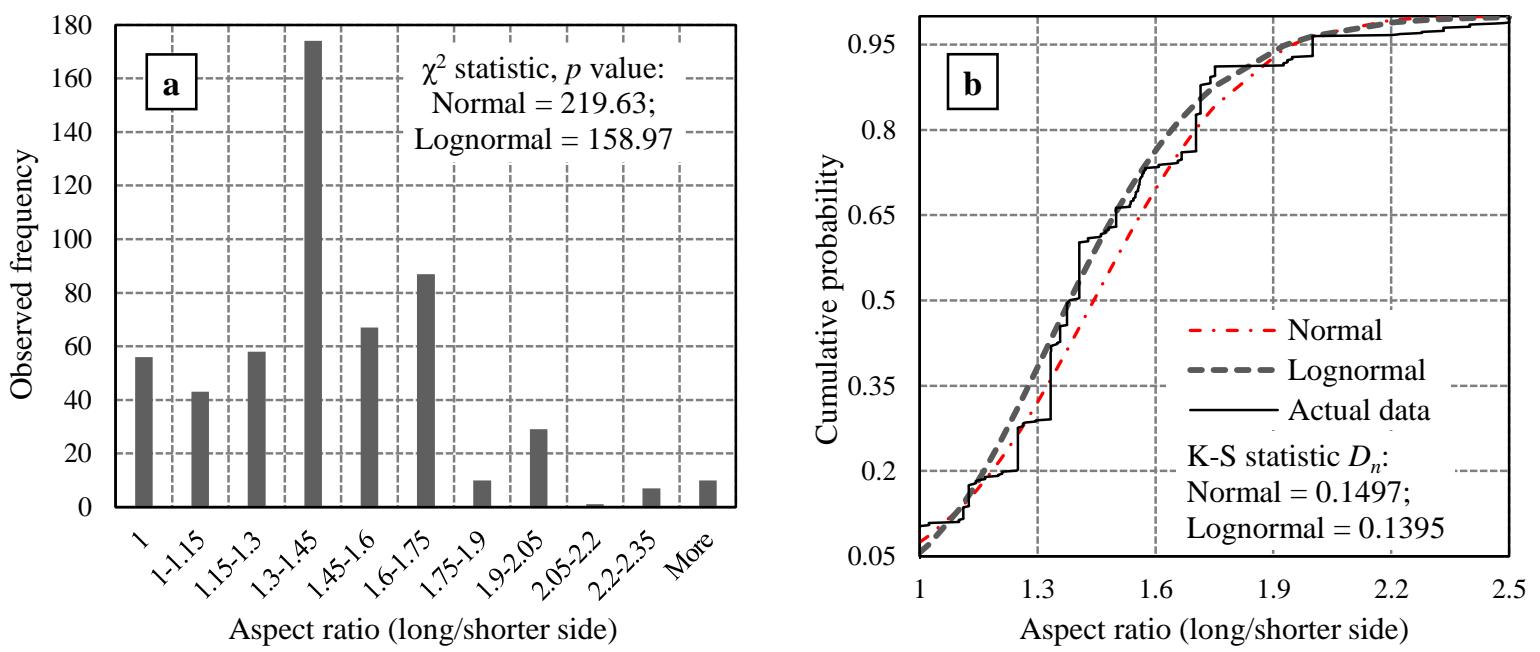

Figure 4: (a) Histogram of collected data; and (b) fitted cumulative distribution functions for ceiling aspect ratios.

Since the area and the aspect ratio in this equation follow a probabilistic distribution, MC simulation is used to combine these two distributions and to generate the distribution of the longer side length of ceiling. The resulting cumulative distribution (average corresponding to the 10,000 simulations) of the longer side of ceilings is presented in Figure 5.

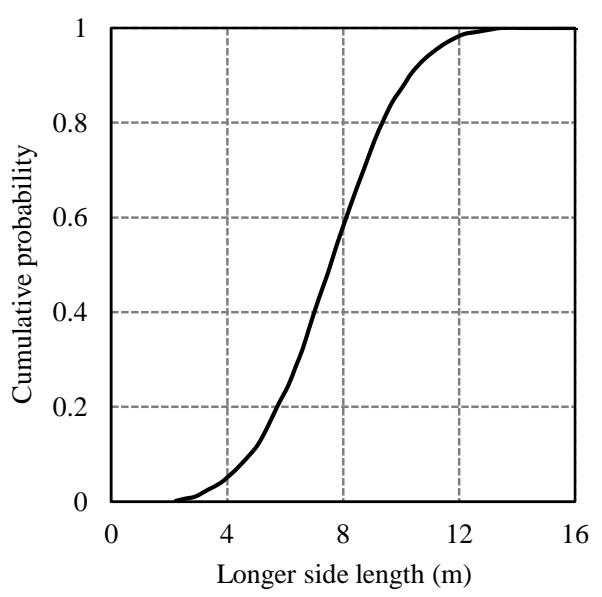

Figure 5: Cumulative probability distribution of longer side length of ceilings.
Development of Generalized Loss Function for Suspended Ceilings

\section{Generalized Fragility Function for Typical Ceiling Systems}

This section aims to develop a generic fragility function which provides the probability of failure in a suspended ceiling at any given floor acceleration and for any given ceiling size. For the purpose of this study, the relationship between the peak accelerations at the floor level and ceiling level has not been taken into account. Therefore, the acceleration used while developing the fragility curves is assumed to be the peak acceleration applied on the ceiling grids and connections. The values of acceleration applied on the ceiling system can be up to two times higher than the PFA depending on the period of the ceiling system [22]. By combining the distribution of longer side length of the ceiling with the benchmark fragility function for a standard length, generalized fragility functions for any ceiling size can be generated. The following paragraphs describe the details of this process.

Paganotti et al. [29] tested a large number of grid members and connections of a typical suspended ceiling system. Based on the component test results, they developed fragility functions for ceilings with different sizes in the longitudinal direction. The fragility curve produced in their study was based on the $2.4 \mathrm{~mm}$ rivet (i.e. rivet having $2.4 \mathrm{~mm}$ diametre) connections between the perimetre angle and the grid 
members. The ceiling measured $12 \mathrm{~m}$ in the longer direction, and its unit weight was approximately $10.5 \mathrm{~kg} / \mathrm{m}^{2}$. Since many suspended ceilings in New Zealand currently use $3.2 \mathrm{~mm}$ rivets, a fragility curve is developed for a suspended ceiling category of the same unit weight and length, however with 3.2 $\mathrm{mm}$ rivet for the perimetre connection. Table 1 shows the shear capacity of different rivet sizes. A third fragility curve is developed for a ceiling category with $3.2 \mathrm{~mm}$ rivets but lighter unit weight. The total unit weight of the third ceiling is assumed as $6.5 \mathrm{~kg} / \mathrm{m}^{2}$. These additional two curves are produced based on the fragility curves of most critical ceiling components [30]. Figure 6(a) shows these three fragility curves corresponding to different rivet sizes and unit weights. Table 2 shows the values of median and standard deviation of the acceleration capacity corresponding to the three ceilings evaluated here.

Table 1: Shear and tensile strength of aluminium rivets [31]

\begin{tabular}{ccc}
\hline Diameter & Shear strength $(\mathbf{k N})$ & Tensile strength $(\mathbf{k N})$ \\
\hline $2.4 \mathrm{~mm}$ or $3 / 3^{\prime \prime}$ & 0.400 & 0.534 \\
$3.2 \mathrm{~mm}$ or $1 / 8^{\prime \prime}$ & 0.756 & 0.979 \\
\hline
\end{tabular}

Table 2: Values of median and standard deviation for ceilings

\begin{tabular}{cccc}
\hline $\begin{array}{c}\text { Weight } \\
\left(\mathbf{k g} / \mathbf{m}^{2}\right)\end{array}$ & $\begin{array}{c}\text { Rivet size } \\
(\mathbf{m m})\end{array}$ & $\begin{array}{c}\text { Median } \\
(\mathbf{g})\end{array}$ & $\begin{array}{c}\text { Standard deviation } \\
(\mathbf{g})\end{array}$ \\
\hline 10.50 & 2.4 & 0.52 & 0.235 \\
10.50 & 3.2 & 1.00 & 0.120 \\
6.50 & 3.2 & 1.63 & 0.195 \\
\hline
\end{tabular}

The seismic force in ceiling components is directly related to the seismic weight applied on it. Therefore, the maximum seismic force induced in a ceiling can be assumed directly proportional to the length of the ceiling or the length of grid member [30]. In other words, the floor acceleration a ceiling can sustain decreases linearly with the ceiling length. Consequently, knowing the failure probability of the $12 \mathrm{~m}$ long ceiling at a given acceleration, the failure probability of ceilings of different lengths at the same acceleration can be computed. Generalising this interrelationship, the converted acceleration capacity $\left(a_{L}\right)$ of ceilings with a longer side length of $L$, can be obtained as,

$a_{L}=\frac{12}{L} \times a_{12}$

where, $a_{12}$ is the acceleration capacity of a $12 \mathrm{~m}$ long ceiling system.

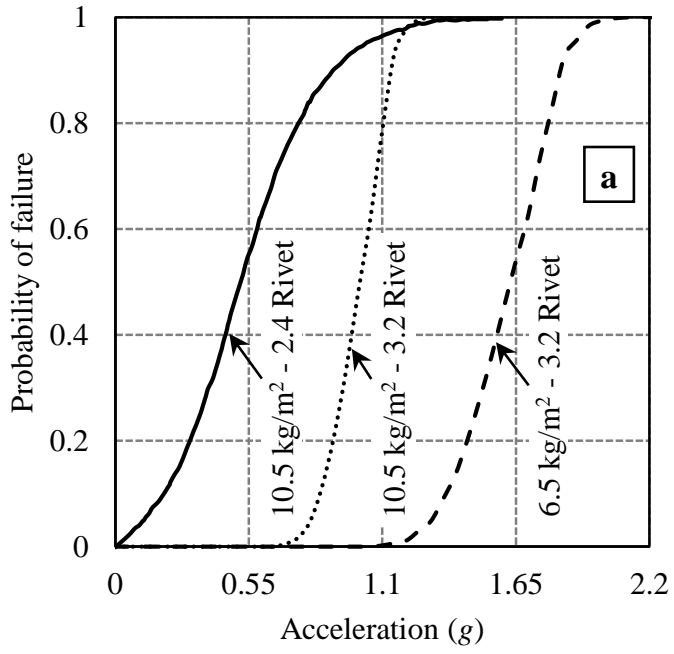

Once again, as the longer dimension of ceilings follows a statistical distribution, MC simulation is performed to obtain the distribution of the converted accelerations. For a given acceleration (say $0.1 \mathrm{~g}$ ), a random value of the longer side length is generated conforming to the previously defined distribution (Figure 5). The acceleration (i.e. $0.1 \mathrm{~g}$ ) corresponding to the generated length is then converted to a 12 $\mathrm{m}$ ceiling length using Equation 4. The probability of failure corresponding to the converted acceleration is obtained for each ceiling type using the benchmark fragility curves (i.e. Figure 6(a)) developed for a $12 \mathrm{~m}$ ceiling length. This failure probability is taken as the probability of failure of a ceiling of the generated length when subjected to the given acceleration (i.e. $0.1 \mathrm{~g}$ ). The procedure is then repeated for multiple length realizations. The mean failure probability of the ceiling type (independent of the length) subjected to the original floor acceleration (i.e. $0.1 \mathrm{~g}$ ) is then obtained by taking the average value of the calculated failure probabilities. The procedure is repeated for various accelerations, and the resulting generic mean fragility functions of ceiling systems independent of the size can be generated as shown in Figure 6(b).

Figure 6(b) indicates that the probability of ceiling failure becomes immediately significant at near-zero accelerations for the $10.5 \mathrm{~kg} / \mathrm{m}^{2}$ ceiling with $2.4 \mathrm{~mm}$ rivets; this is partly a byproduct of the probabilistic derivation process and partly due to the vulnerability of large sized ceilings even at small accelerations. It is noted that only one damage state (termed as failure) is used in the ceiling fragility. Failure of ceilings in this context refers to the state where the ceiling grids supporting the tiles fail at one point, which triggers successive falling of the ceiling tiles. At this damage state, it is economically and technically not efficient to repair the ceilings, consequently replacement of the ceilings is an obvious choice. It is worth mentioning that other damage states corresponding to the falling of some tiles without damaging the grid members are not considered in this study. This is justifiable as the repair costs corresponding to these damage states are insignificant as compared to the replacement of complete grid. Although, the repair cost is negligible corresponding to these damage states, dislodgement of few tiles and/or minor damage to the grid members (not complete failure) are not rare, particularly at the lower levels of acceleration. Therefore, other limit states as defined by Badillo-Almaraz et al. [32] and other researchers can be considered in the calculation when more refined seismic loss estimation is necessary.

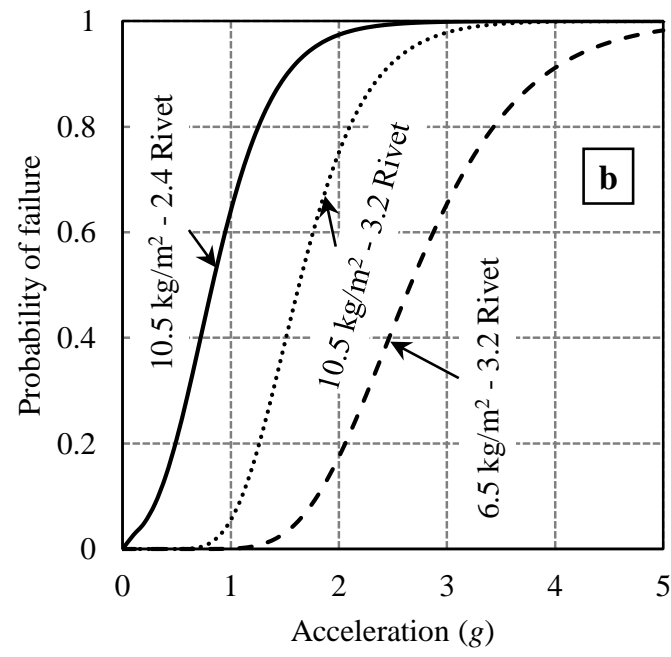

Figure 6: (a) Fragility curve for 12 m long suspended ceilings; (b) generalized fragility functions of typical suspended ceilings. 


\section{Replacement Cost for Suspended Ceilings}

To derive a generic loss function, which indicates the likely replacement cost of typical ceiling systems subjected to a given acceleration, information on the replacement cost of various types of ceilings with different configurations was collected. The information on the replacement cost of the ceilings was obtained from local builders, some of the ceiling suppliers in New Zealand (Armstrong ${ }^{\mathrm{TM}}$ [25] and USG Boral $^{\mathrm{TM}}$ [33]), from employees of construction companies, and the price range in Rawlinson's construction handbook [34]. Information received from more than 15 sources, including internet listing and random construction workers, were considered. The relatively small sample size is assumed sufficient for this study. The collected data was fitted to a normal distribution. The mean and standard deviation of the replacement cost per square metre of suspended ceilings were amounted to NZ\$93.5 and NZ\$5.83, respectively.

\section{Generic Expected Loss Function for Typical Ceilings}

As the generic fragility distinguishes between only "collapse" and "no collapse" without considering any other intermediate damage states (for the reasons explained earlier), the financial loss comes from the probability of damage requiring the compete ceiling system to be replaced. Considering only one damage state, Equation 1 can be rewritten for per square metre of ceiling as,

$$
L_{\text {ceiling/PFA }}=P(F \mid P F A) \times l_{\text {ceiling }}
$$

where, $L_{\text {ceiling/PFA }}$ is the expected loss per square metre of ceiling; $P(F \mid P F A)$ is the probability of ceiling failure under a given peak floor acceleration (PFA), which can be obtained from the generic fragility functions shown in Figure 6(b); and $l_{\text {ceiling }}$ is the cost of ceiling replacement. It is worthy to mention that the actual acceleration at the ceiling level, instead of $P F A$, needs to be evaluated for accurate estimation of the ceiling loss.

Combining the distributions of the collected data on the replacement cost and the generic ceiling fragility functions (Figure 6(b)), 10,000 MC simulations are performed using Equation 5 to generate a large number of values of the expected loss per square metre of ceilings for a chosen value of $P F A$. The process is repeated for different $P F A$ values. The

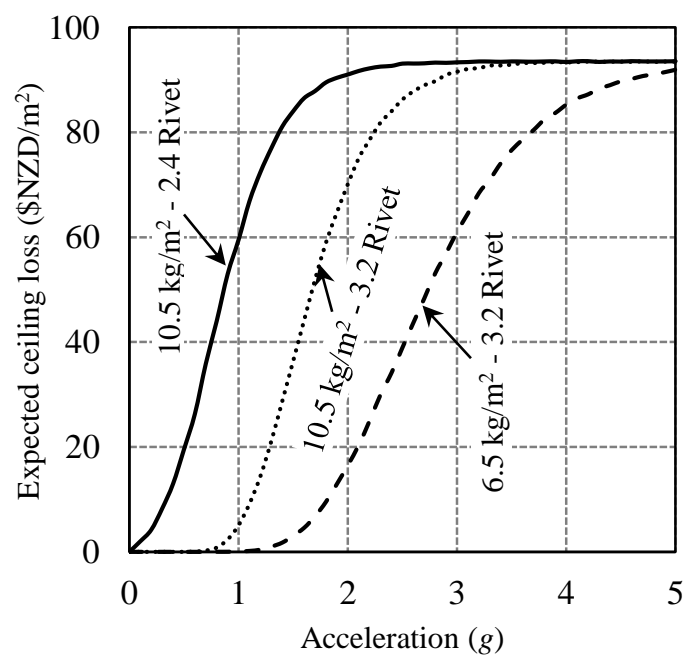

(a) resulting average expected loss due to damage to the ceilings at various acceleration levels is shown in Figure 7(a). The estimated loss shown in this figure is independent of the room size and longer side length of ceilings, therefore can be used for various applications. However, the expected loss shown in this graph is obtained based on the data collected in New Zealand and Christchurch in particular. Therefore, it may not be directly applicable for other locations due to variation of prices in different places.

In order to be able to generalize the model, the expected loss can be normalized with respect to the total cost of office buildings per square metre of floor area. By collecting building cost (range) from several building practitioners, and analysing the collected data, the mean and standard deviation of total building construction cost per square metre of floor area were estimated as NZ\$2034 and NZ\$213, respectively. It is noted that the data used to obtain this result is from the construction cost of office buildings in Christchurch CBD. The majority of the buildings in this research are low to medium-rise buildings. It is likely that the variation of the building construction cost data might have been wider if a greater variety of building height was considered in the data collection.

Since the total construction cost of buildings is uncertain, and follows a distribution (fitted to a normal distribution in this study), MC simulation was performed to normalize the expected ceilings loss with respect to the total building cost. The resulting normalized expected loss corresponding to typical ceiling systems with respect to the acceleration is shown in Figure 7(b). The normalized expected loss represents the ratio between the expected cost of replacing damaged ceilings and the total building cost. Knowing the acceleration induced at each storey level, this curve enables a fast prediction of the expected loss due to ceilings regardless of their size, and without requiring any information regarding the fragility of ceilings. As can be seen in the figure, the expected loss due to ceilings is around $4.5 \%$ of the total building cost at large accelerations for which the failure probability is significantly high. At an acceleration of $1 \mathrm{~g}$, the minimal improvement of grid fixture from $2.4 \mathrm{~mm}$ rivet to $3.2 \mathrm{~mm}$ rivet reduces the loss ratio from $3 \%$ to $0.3 \%$. Similarly, using lighter ceiling tiles is effective in reducing the overall expected loss due to ceiling failure.

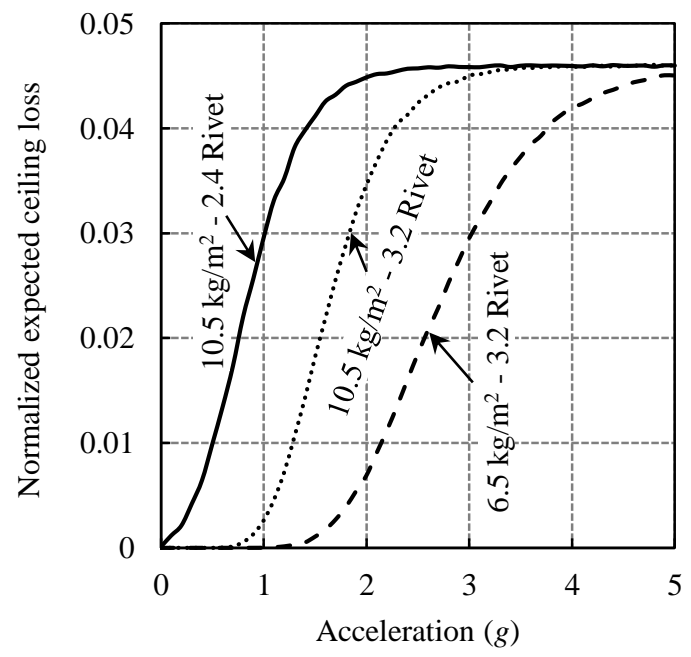

(b)

Figure 7: (a) Generalized expected loss curves of typical ceilings; (b) generalized and normalized (in terms of total building cost) expected loss curves of typical ceilings. 


\section{Case Study}

To examine the accuracy of the generic loss function developed in the previous section, the expected loss attributed by the ceiling replacement cost of a case study building is computed through a rigorous approach, and compared with the same obtained using the developed generic loss function. For this case study, the loss data associated with only one of the three variations of ceilings, i.e. the ceiling with $2.4 \mathrm{~mm}$ rivet connections are used. The case study building is the engineering building of the University of Canterbury, Christchurch. This is a five storey RC building and each floor is used for different purpose. The first and second floors accommodate several lecture rooms, self-study rooms and a large computer laboratory room for undergraduate students. Similarly, postgraduate research rooms and a large drafting room are located on the $3^{\text {rd }}$ floor, and the top two floors of the building are used as offices for the academic staff. The floor area at each storey level is approximately $1680 \mathrm{~m}^{2}$.

Since the detailed architectural and structural drawings for the case study building were available, a detailed and reasonably accurate estimation of the expected loss due to the failure of the ceilings with respect to the total cost of the building is carried out. As the ceilings' area and longer dimension are known precisely, the uncertainty due to these variables is omitted in the estimation. Hence, the ceiling cost is the only uncertain parametre in this calculation. The first step in the assessment of loss is prediction of engineering demand parametres, i.e. peak floor accelerations in this case. To estimate the peak floor acceleration at each storey level, the method stipulated in New Zealand Standard [22] is utilized. Note that, here the peak accelerations at the ceiling levels are assumed to be same as PFAs for simplicity, however in practice it can be significantly higher than the $P F A$.

The following steps are performed to assess the expected loss due to failure of the ceilings for the case study building.

(i) For the given floor level and limit state under consideration, calculate the floor acceleration demand using the NZS1170.5 [22] approach. The accelerations at the ceiling level need to be considered for a more accurate estimate.

(ii) Create a database of dimensions of all rooms in all floors of the building.

(iii) Group the rooms according to their longer dimension; put rooms with lengths within a predefined interval in the same category.

(iv) Calculate the mean value of the longer dimension (i.e. length) of each group.

(v) For the mean value of longer dimension, calculate the acceleration capacity of the ceilings using Equation 4 and generate the fragility curve/function (by converting Figure 6(a)).

(vi) Estimate the failure probability of each group of ceiling using the fragility function.

(vii) Within each group, sub-group the rooms according to their shorter side lengths (close to each other within a predefined interval).

(viii) Count the number of rooms in all sub-groups. (ix) Using the mean value of the longer and shorter dimensions, calculate the mean area for all sub-groups.

(x) For all sub-groups, multiply the failure probability by the mean ceiling area, number of rooms and mean ceiling replacement cost per unit area to obtain the expected ceilings loss.

(xi) Obtain the total ceiling replacement cost for the floor by adding the calculated losses from all groups/sub-groups of ceilings.

(xii) Divide the total cost by the total area of the ceilings in the floor to obtain the average expected ceiling loss per square metre.

The above steps were repeated for all five floors in the building. Note that the New Zealand Standard [22] requires suspended ceilings in normal buildings to be designed for the serviceability limit state (SLS). The natural period of the case study building is computed to be about $0.6 \mathrm{sec}$. The peak floor accelerations corresponding to the serviceability level earthquake (25 year return period) are calculated as $0.32 g$, $0.43 g, 0.53 g, 0.64 g$ and $0.64 g$, at the $1^{\text {st }}, 2^{\text {nd }}, 3^{\text {rd }}, 4^{\text {th }}$ and $5^{\text {th }}$ floor level, respectively. The peak floor accelerations at other seismic intensity levels can be computed as per the standard procedure explained in NZS1170.5 [22]. As an example, the estimated values at each step are shown in Table 3 for the $4^{\text {th }}$ floor of the case study building for the SLS. As can be seen from the table, the expected loss associated with ceilings is estimated as NZ\$29 per square metre area of the floor.

Alternatively, ceiling losses can also be estimated using the loss function developed herein at the acceleration level corresponding to the required hazard level. Figure 8 shows a comparison between the expected ceiling losses estimated using the generic loss function and those obtained by the detailed loss assessment for the case study building for six different return periods. Rather than showing the mean value of the ceiling loss predicted by the loss function, a range of values between the $5 \%$ to $95 \%$ confidence intervals are highlighted.

It is evident from Figure 8 that ceiling losses in the case study building fall within the $90 \%$ confidence interval of the approximate method (i.e. using the generic expected loss function) for all cases except a couple of floors at 25 and 50 year return periods. For most floors of the case study building, the detailed loss assessment generally results in lower ceiling losses than the median loss given by the generic loss function (slightly conservative). For return periods of 25 and 50 years, the exact ceiling loss in the $3^{\text {rd }}$ floor is higher than that given by the loss function developed in the paper. This difference for the third floor is probably due to the presence of large amount of open spaces (the drawing room), which has a disproportionately long ceiling compared to the median value of longer dimension of the rooms. However, the close agreement between the average losses given by the loss function with the calculated loss for the case study building in general suggests that the proposed function can be relied on as a quick and simple tool to estimate expected seismic loss resulting from damage to suspended ceilings under different floor accelerations. 
Table 3: Expected loss due to ceiling for $4^{\text {th }}$ floor of engineering building

\begin{tabular}{|c|c|c|c|c|c|c|c|}
\hline $\begin{array}{l}\text { Longer } \\
\text { side (m) }\end{array}$ & $\begin{array}{c}\text { Average } \\
\text { length }(m)\end{array}$ & $\begin{array}{c}\text { Failure } \\
\text { probability }\end{array}$ & $\begin{array}{l}\text { Shorter } \\
\text { side }(\mathrm{m})\end{array}$ & $\begin{array}{l}\text { No. of } \\
\text { rooms }\end{array}$ & $\begin{array}{c}\text { Average } \\
\text { area }\left(\mathbf{m}^{2}\right)\end{array}$ & $\begin{array}{c}\text { Total } \\
\operatorname{area}\left(\mathbf{m}^{2}\right)\end{array}$ & $\begin{array}{c}\text { Loss } \\
(\mathbf{N Z \$ )}\end{array}$ \\
\hline \multirow{3}{*}{2 to 4} & \multirow[t]{3}{*}{, } & \multirow{3}{*}{0.087} & 1.5 to 2 & 7 & 5.25 & 36.75 & 299 \\
\hline & & & 2 to 3 & 40 & 7.5 & 300 & 2,440 \\
\hline & & & 2 to 3 & 0 & 0 & 0 & 0 \\
\hline \multirow{5}{*}{5 to 6} & \multirow{5}{*}{5.5} & \multirow{3}{*}{0.184} & 3 to 4 & 0 & 0 & 0 & 0 \\
\hline & & & 4 to 5 & 24 & 24.75 & 594 & 10,217 \\
\hline & & & 5 to 6 & 0 & 0 & 0 & 0 \\
\hline & & \multirow{5}{*}{0.503} & 2 to 3 & 0 & 0 & 0 & 0 \\
\hline & & & 3 to 5 & 0 & 0 & 0 & 0 \\
\hline \multirow[t]{5}{*}{10 to 11} & \multirow[t]{4}{*}{10.5} & & 5 to 6 & 13 & 57.75 & 750.75 & 35,272 \\
\hline & & & 6 to 7 & 0 & 0 & 0 & 0 \\
\hline & & & 7 to 11 & 0 & 0 & 0 & $\$ 0$ \\
\hline & & \multicolumn{2}{|c|}{ Total } & & & 1681.5 & 48,227 \\
\hline & \multicolumn{4}{|c|}{ Expected loss (rounded off) } & & \multicolumn{2}{|c|}{$29\left(\mathrm{NZ} \$ / \mathrm{m}^{2}\right)$} \\
\hline
\end{tabular}

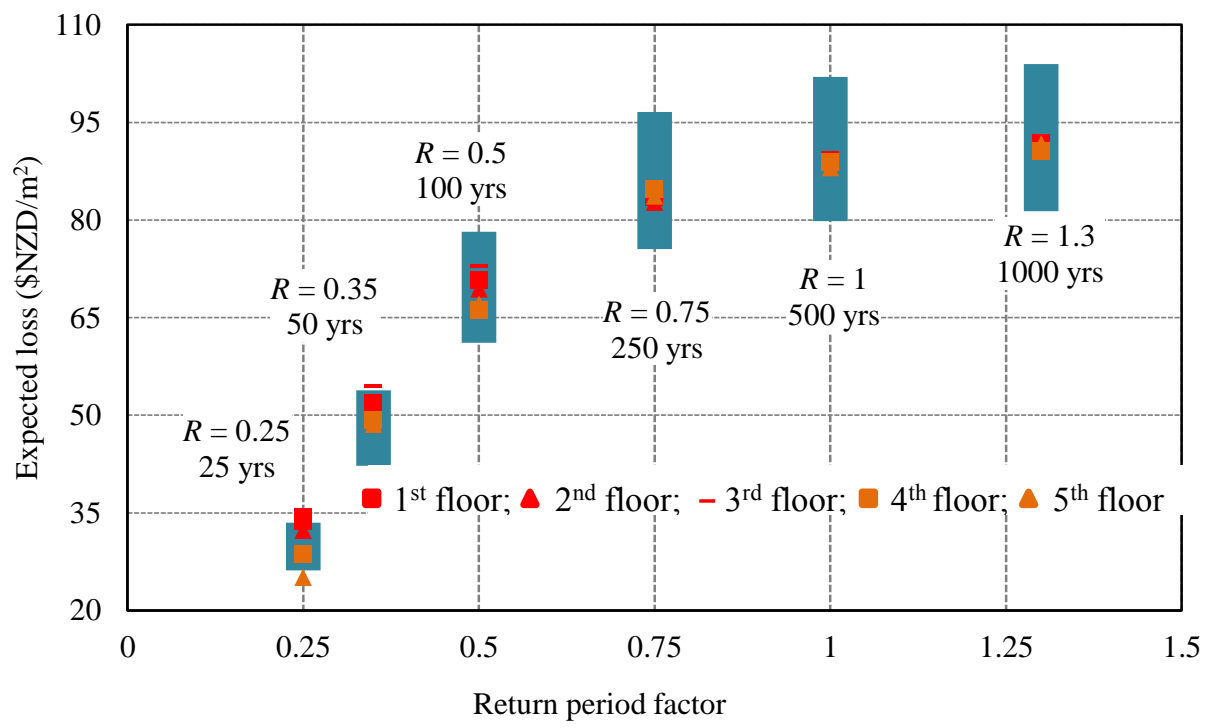

Figure 8: Comparison of calculated expected losses due to ceilings for case study building with the generic expected loss function predictions.

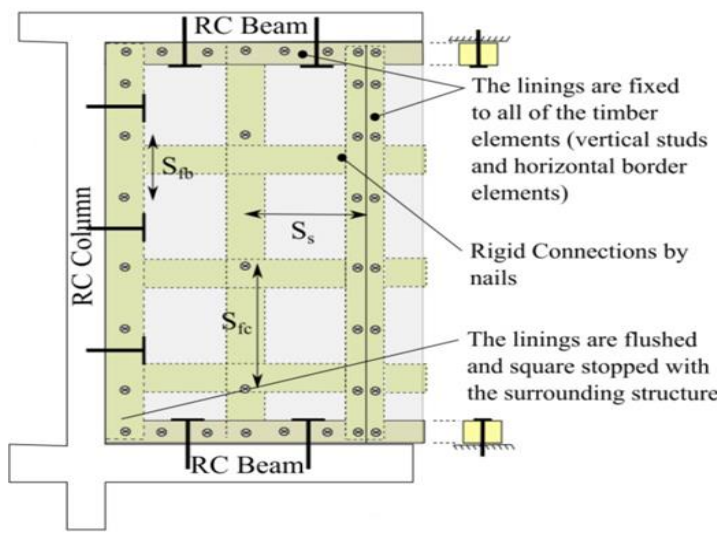

Figure 9: Typical timber-framed partition wall [35].

\section{SECTION II: PARTITION WALLS}

A partition wall is a non-structural component located within structural frames of a building in order to separate rooms. The most common partition wall types used in New Zealand are timber framed or steel framed partitions sheathed with drywall boards (Figure 9). Despite their significance, building codes do not have specific guidelines that help to reduce the damage of partition walls and their contribution to the seismic loss of buildings. For the drywall partition construction, manufacturers' specifications are normally used to meet the standard for the finishing of gypsum linings [36]. Behaviour of drywall partitions subjected to shear loading was previously studied by Lee et al. [37], where the relationship between the inter-storey drift and damage to drywall partitions was developed under quasi-static cyclic loading conditions. Partition walls have proven to be influenced even by small drift levels; and as a result, suffer severe damage.

\section{Distribution of Partition Walls in Office Buildings}

In order to establish the distribution of partition walls in office buildings, the total length of partition walls and the floor area were collected from several office buildings in Christchurch. For this purpose, drawings of a large number of Christchurch buildings damaged in the 2010-2011 Canterbury earthquakes were accessed. However, the partition layout is not usually decided until later in the design and construction process. Hence, most of the drawings in the archive did not include final architectural plans, and those which did, had insufficient information for the layout of partition walls; thereby making this phase more difficult than anticipated. Although a library of drawings corresponding to 725 rooms from 29 different office buildings located in Christchurch CBD were searched, a data set of 98 office floors could be collected that contained sufficient information about the partitions. The length of partition walls was established by measuring the length individually for each floor. The height, width, material used and number of door openings for the partitions were also recorded at this stage. These were then used to calculate the expected ratio of the partition wall length to the floor area for a typical office building in Christchurch, which is expected to represent the trend in New Zealand. The number of data is 
assumed sufficient to represent the distribution of the partition ratio $(R=$ length of partition / floor area) for typical office buildings in New Zealand. Floor wise distributions of the partitions were not considered. The assumptions made during the data collection were:

(i) Doors act as partitions and were included in the overall length of partition wall.

(ii) Elevator shafts and staircases were considered to be structural component and not included in the calculation.

(iii) Non-office related floors were ignored.

(iv) If not explicitly stated, floor areas were assumed to be consistent throughout a building.

The histogram and the cumulative probability distribution of the observed partition ratios are presented in Figures 10(a) and 10(b), respectively. Two theoretical CDFs, normal and lognormal, are also presented in Figure 10(b). The observed data are fitted with normal distributions (mean $=0.23 \mathrm{~m} / \mathrm{m}^{2}$, standard deviation $=0.058 \mathrm{~m} / \mathrm{m}^{2}$ ) and lognormal distributions (median $=0.22 \mathrm{~m} / \mathrm{m}^{2}$, logarithmic standard deviation $=0.293$ $\mathrm{m} / \mathrm{m}^{2}$ ). Based on the GOF tests, it is concluded that the normal distribution gives a better representation of the partition ratios.

\section{Development of Generalized Loss Function for Partitions}

\section{Damage States and Fragility Functions for Partition Walls}

The cost of repair/replacement for a partition wall can be different based on the extent of the damage incurred. Hence, to facilitate loss estimation, damage states should have reasonable correlation with available repair methodology/technology. In this study, the following three damage levels are used to describe the damage to partition walls.

(i) Minor visible damage (DS1): cracking of the paint and/or drywall requiring taping and/or putty then painting.

(ii) Moderate damage (DS2): broken drywall panel requiring replacement of the drywall panel but not the frame.

(iii) Full replacement (DS3): damage to the panels and frame requiring full replacement of the partition wall system.

It has extensively been shown that damage in partition walls can be attributed to the inter-storey drift experienced by the storey accommodating the partition wall. Porter and

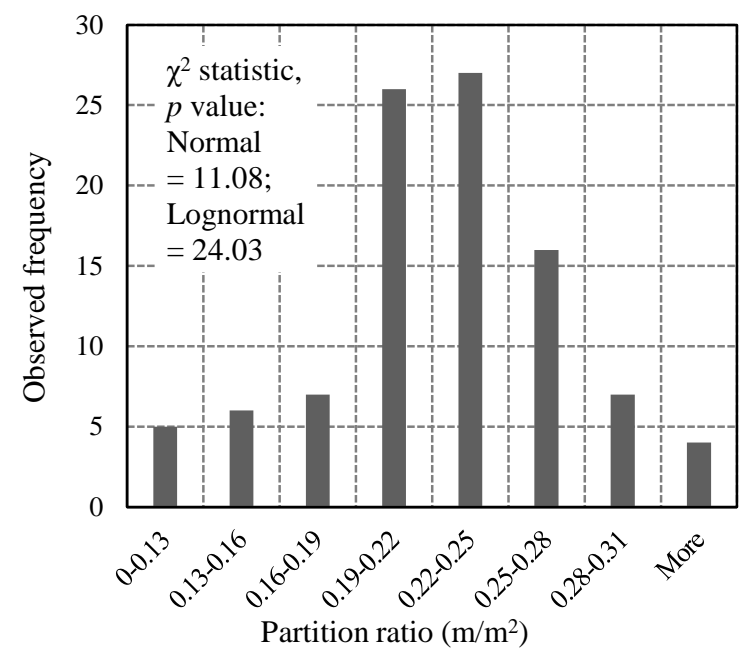

(a)
Kiremidjian [38] developed fragility functions for a number of different non-structural components of a building. The partition wall fragility function established in their study is used for modelling the damage to partition walls in this study.

Note that the fragility function proposed by Porter and Kiremidjian [38] was based on the experiments conducted by Rihal [39]. This investigation was completed using $2.4 \mathrm{~m} \times$ $2.4 \mathrm{~m}$ partition panels that were $16 \mathrm{~mm}$ thick and fixed onto $92 \mathrm{~mm}$ metal studs using screw fasteners. This may not fit perfectly to the partitions that are likely to be found in Christchurch but it was assumed that it would provide a close enough fit. Typical partition walls in New Zealand are made with gypsum boards, which come in a variety of heights (2 - 3 $\mathrm{m})$ and thicknesses $(10-20 \mathrm{~mm})$. These gypsum boards are fastened to steel or timber studs at $600 \mathrm{~mm}$ intervals. The overall thickness of the wall is typically $120 \mathrm{~mm}$. The two damage levels investigated by Porter and Kiremidjian [38] were stated to have the following repair properties: (i) the partition requires taping and pasting of wall cracks (DL1), and (ii) full damage of the partition wall requiring replacement (DL2). Fitting the test results with lognormal distributions, the fragility functions for the two damage levels were given. The median drift $\left(x_{m}\right)$ and dispersion $(\beta)$ corresponding to the defined damage levels are presented in Table 4.

These two damage levels map reasonably well with two of the damage levels required in this study (DL1 $\approx$ DS1 and DL2 $\approx$ DS3). However, a third fragility curve is introduced in this study for DS2. The moderate damage level is assumed to lie between DL1 and DL2, and is assigned the median drift and dispersion of 0.0058 and 0.19 , respectively. With these values, the three fragility functions used in this research are shown in Figure 11. For clarity, the probabilities of failure corresponding to these three damage states as per Equation 2 are also presented for a particular inter-storey drift ratio $(I D R)$ level. At $I D R=0.007, P_{1}\left[=P\left(D_{1} \mid I D R=0.007\right)\right], P_{2}\left[=P\left(D_{2} \mid\right.\right.$ $I D R=0.007)]$ and $P_{3}\left[=P\left(D_{3} \mid I D R=0.007\right)\right]$ are obtained as $0.12,0.64$, and 0.24 , respectively.

Table 4: Fragility curve parameters (median drift ratio and dispersion)

\begin{tabular}{ccc}
\hline Damage level & $\boldsymbol{x}_{\mathbf{m}}$ & $\boldsymbol{\beta}$ \\
\hline DL1 & 0.0039 & 0.17 \\
DL2 & 0.0085 & 0.23 \\
\hline
\end{tabular}

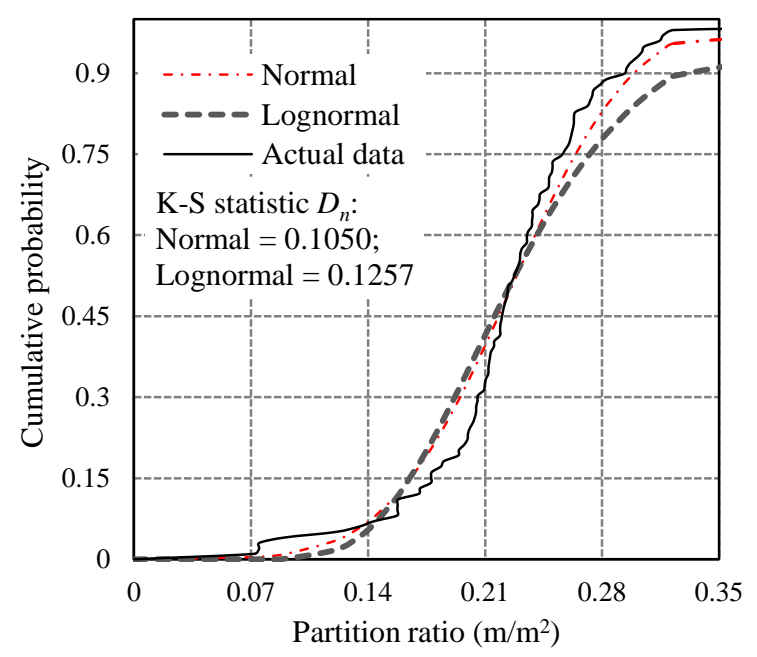

(b)

Figure 10: (a) Histogram of the collected data; and (b) fitted cumulative distribution functions for partition ratio. 


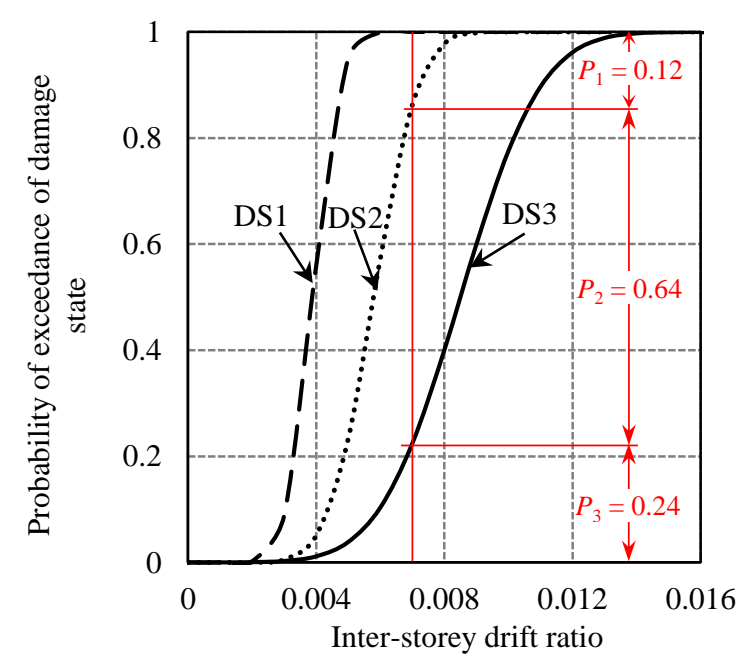

Figure 11: Drywall partition fragility functions for different damage states.

Table 5: Repair/replacement costs for different damage states of partition wall

\begin{tabular}{ccc}
\hline Damage state & $\begin{array}{c}\text { Average repair cost } \\
\left(\mathrm{NZ} \$ / \mathrm{m}^{2}\right)\end{array}$ & $\begin{array}{c}\text { Standard deviation } \\
\left(\mathrm{NZ} \$ / \mathrm{m}^{2}\right)\end{array}$ \\
\hline DS1 & 26.6 & 6.99 \\
DS2 & 61.8 & 6.27 \\
DS3 & 115.9 & 21.07 \\
\hline
\end{tabular}

\section{Partition Repair Costs}

In order to obtain the likely cost to repair the damage mentioned in the previous section, a number of mediums were investigated. This included consulting builders, partition suppliers, construction companies and quantity surveying guides such as Rawlinson's construction handbook [34]. The reluctance of suppliers and contractors to provide estimates for a project leads to a small sample of costs. The data was collected from 15 sources, which is assumed sufficient for this study. The small data set is the reason for the reasonably high standard deviations. The majority of this data was sourced through discussions with builders. As it would be difficult for suppliers and builders to provide accurate costs, a range was accepted. These costs are applicable only to the Christchurch area due to the economic environment. They are also subject to change with variations in economic and industrial

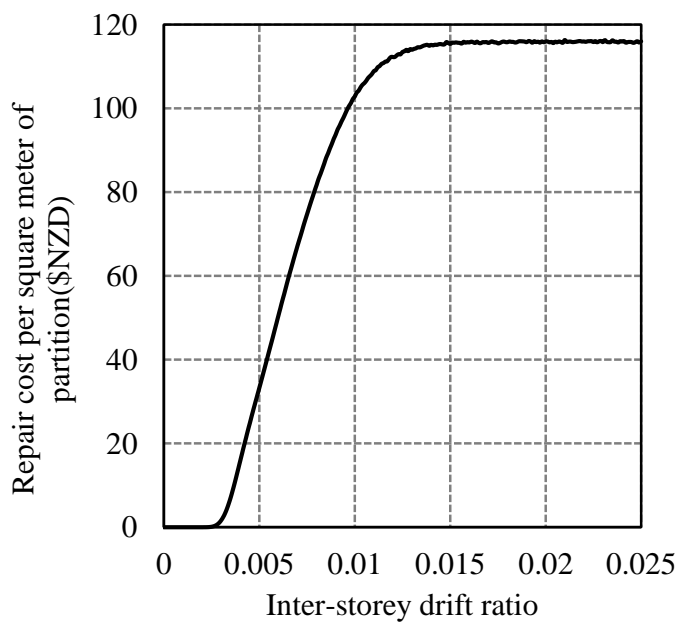

(a) conditions. In this study, the cost data is fitted to a normal distribution. The results of the repair cost data collections for the three damage states mentioned earlier are presented in Table 5 .

\section{Generic Expected Loss Function for Drywall Partition}

Considering three damage states in Equation 1, expected seismic loss for per square metre of drywall partition can be expressed as,

$L_{\text {partition } / D R}=P_{1} \times l_{\text {partition } / D_{1}}+P_{2} \times l_{\text {partition } / D_{2}}+P_{3} \times l_{\text {partition } / D_{3}}$

where, $L_{\text {partition/IDR }}$ is the expected loss per square metre of drywall partition; $P_{1}, P_{2}$ and $P_{3}$ are the probabilities of attaining DS1, DS2 and DS3, respectively, at a given IDR level as shown in Figure 11; and $l_{\text {partition/ } D_{1}}, l_{\text {partition } / D_{2}}$ and $l_{\text {partition } / D_{3}}$ are the cost of partition repair/replacement corresponding to the three damage states DS1, DS2 and DS3, respectively.

To account for the propagation of different uncertainties, MC simulations are carried out using MATLAB ${ }^{\circledR}$ to combine the collected cost data with the fragility functions and to obtain a range of expected loss per square metre of partition at different drift levels. At each drift level, the probabilities of failure are obtained using Equation 2. The repair/replacement cost corresponding to each damage state is then randomly selected from the idealized distribution of costs. Expected repair/replacement cost is calculated repeatedly for $10,000 \mathrm{MC}$ simulations using Equation 6 at a given drift level. The average expected repair/replacement cost per square metre of partition is presented with respect to the IDR in Figure 12(a).

If needed, the costs shown in Figure 12(a) can be presented as a percentage of the full replacement cost of the partition. Such a relation may be more useful as the normalisation will make it applicable to construction outside Christchurch as well. The result of such a normalisation is shown in Figure 12(b). However, as the collected data shows that the replacement cost also has substantial uncertainty, using the mean replacement cost will not propagate this uncertainty, and another MC simulation will be needed to get normalized partition repair cost with different confidence levels.

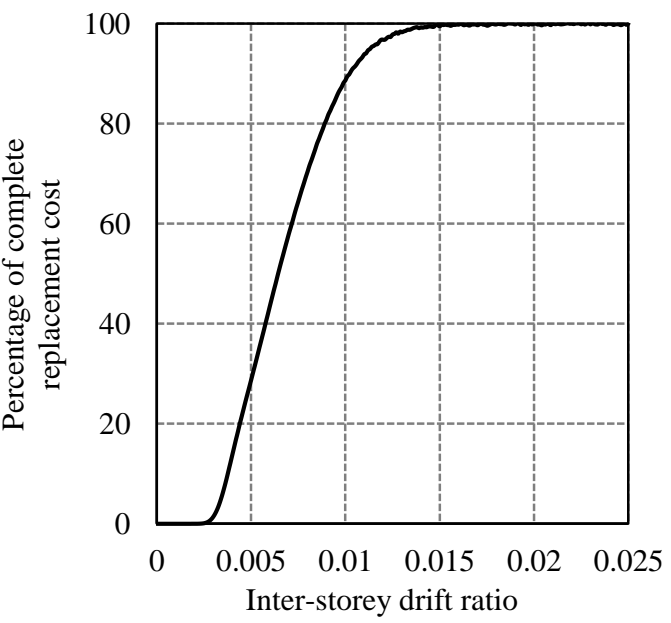

(b)

Figure 12: (a) Repair cost per partition area vs. inter-storey drift; and (b) percentage of complete partition repair/replacement cost. 


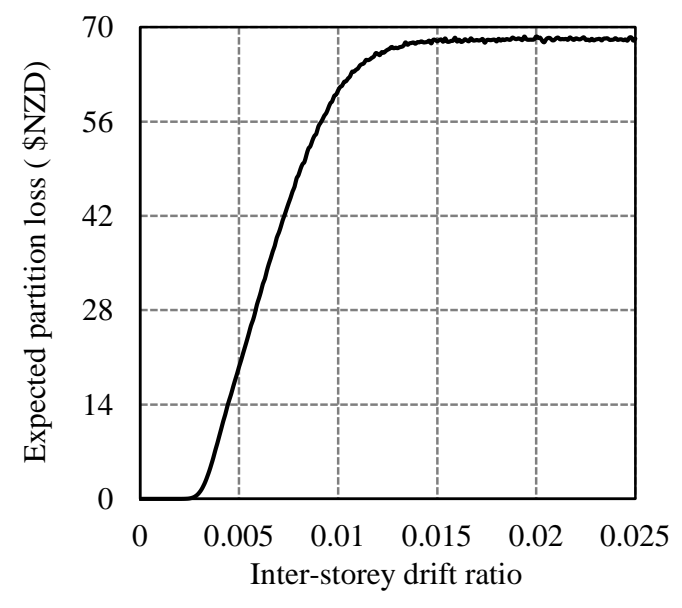

(a)

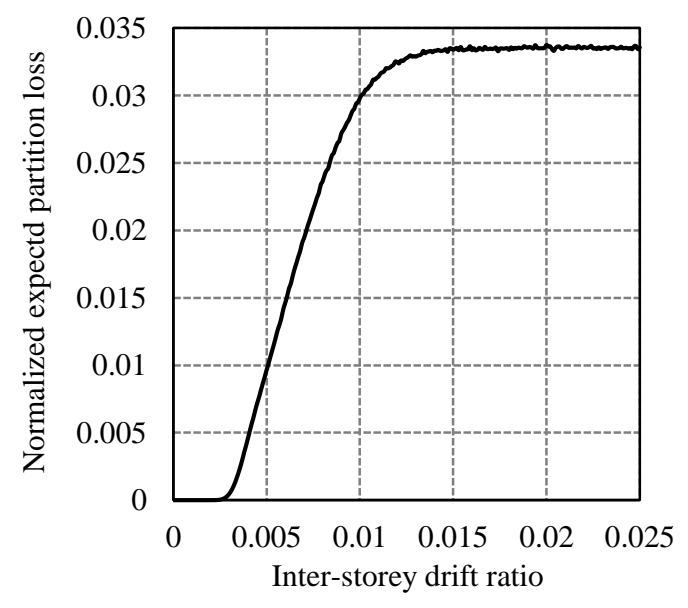

(b)

Figure 13: (a) Generalized expected loss for partitions; and (b) generalized and normalized (in terms of total building cost) expected loss curves for partitions.

The aim of the envisaged generic loss function is to provide the total likely partition loss in a building with a known floor area (without having to measure the partition area). For this purpose, the expected loss function is required to be modified by using the partition ratio as given in Equation 7 .

$$
L_{P}(I D R)=L_{\text {partition } / I D R} \times R_{P} \times H
$$

where, $L_{P}(I D R)$ is the expected loss due to partition damage per square metre of floor area at a given drift level; and $H$ is the average partition wall height. As the height of the partition (loosely equal to storey height) was found to vary little over the building floors, this is considered as a deterministic parameter in the calculation. The uncertainty propagation from $L_{\text {partition/IDR }}$ and $R_{P}$ to the final expected loss due to partition per square metre of floor is addressed using MC simulation.

In this study, Equations 6 and 7 are combined, and a single $\mathrm{MC}$ simulation is conducted by treating the three damage state repair/replacement costs and the partition ratio as primary variables. At each drift level, 100,000 simulations are conducted. Within each simulation, a random partition ratio is generated using the distributions shown in Figure 10(b). Random costs for the three different damage levels were also established using a normal distribution and the costs input from Table 5. The average partition wall height was considered as $2.6 \mathrm{~m}$ based on the collected data. The computed expected losses were averaged to obtain the final expected loss due to partition damage per square metre of floor area at the specified drift level, which is presented in Figure 13(a).

It can be observed in Figure 13(a) that the loss due to partition damage will increase with drift levels to a maximum of NZ\$68 per square metre of office floor area. This is likely to be higher than normal due to the inevitable bias induced by the recent hike in the construction and repair cost owing to the demand surge in Canterbury region. To exclude this bias from the expected loss function, and in order to provide a more versatile representation of the expected loss, the curve can be normalized to the construction cost of the building per square metre of floor area. The results of such a normalization (taking the variation in building cost into consideration) are shown in Figure 13(b). It can now be seen that the likely loss due to partition damage reaches a maximum of $3.4 \%$ of the total cost of a building (approximately). This is a small but significant contribution and the building clients should be acutely aware of this fact.

\section{Case Study}

To confirm the accuracy and feasibility of the generic loss functions developed for partition walls, three case study buildings from the building drawing archive are examined. Actual building plans are to determine the exact size of partition walls in different floors in these buildings. The likely partition losses are calculated separately for each floor using inter-storey drifts estimated for different floors of these buildings corresponding to different hazard levels.

First among the three case study buildings is the nowdemolished 96 Hereford Street in Christchurch. This was a 10 storey RC frame building built in 1987 and founded on deep/soft soil as per geotechnical reports. It consisted of three laterally resisting frames in one direction, and four laterally resisting frames in the other direction. The direction of loading for the analysis is assumed to be in the direction that gave the greatest drift. The building's first three floors were used as retail space, therefore have not been included in the calculation herein.

For comparison with the developed loss function prediction, calculation of partition loss for a design level earthquake with a 500 year return period is explained in detail here. For calculating the inter-storey drifts, the building is represented by a bare 2D frame. The storey forces are calculated by distributing the design base shear as per the equivalent static method stipulated in NZS1170.5 [22]. To calculate the displacements, the ideal rigid-beam shear stiffness of the frame (i.e. number of columns $\times 12 E I / H^{3}$ ) is adjusted to account for the beam flexibility. To adjust the stiffness, the equivalent lateral stiffness for a one-storey frame is determined based on the layout of the first floor of the building. This assumes that the three-bay frame has five degrees of freedom (neglecting the axial deformation of members); out of which the four rotational degrees of freedom are condensed to find an equivalent floor translational degree of freedom. The equivalent shear stiffness of the frame is found to be $65 \%$ of the ideal rigid-beam shear stiffness.

The following steps are used in calculating the drift between different storeys (i.e. EDP for the partition walls in different storeys).

(i) Seismic weights at all floor levels are calculated as per New Zealand Standard [22] excluding the stairwells.

(ii) Effective storey shear stiffness of the laterally resisting frame is estimated as explained above. 
(iii) The natural period of the fundamental mode is estimated using Rayleigh's method.

(iv) The design base shear for the estimated period is calculated and distributed to the floors using the equivalent static method. A ductility of 2 is used in the calculation, which is in line with the ductility used in the assessment of RC buildings designed in the 1980s in New Zealand

(v) Elastic storey drifts are calculated using the storey shear forces and effective shear stiffness.

(vi) The inelastic drifts for all storeys are calculated using a ductility factor of 2 .

The natural period of this structure is estimated as $1.72 \mathrm{sec}$. The estimated inter-storey drift ratios vary between $1.41 \%$ and $0.4 \%$. Using the calculated inter-storey drift and the floor area measured from the building plans, the approximate partition loss in a given floor can be readily determined using the loss function shown in Figure 13(a). Once this is repeated for all floors, the total loss from partitions for the whole building can then be obtained by adding the floor level losses. Thus, the likely partition loss at a design level (i.e. 500 year return period) seismic event as predicted using the proposed loss function comes out to be about NZ\$195,000 (refer to last column of Table 6).

Table 6: Comparison between the calculated partition losses for the 96 Hereford Street Building

\begin{tabular}{cccccc}
\hline & & & \multicolumn{2}{c}{ Partition loss } \\
\hline Floor & $\begin{array}{c}\text { Area } \\
\left(\mathbf{m}^{\mathbf{2}}\right)\end{array}$ & $\begin{array}{c}\boldsymbol{I D R} \\
(\boldsymbol{\%})\end{array}$ & $\begin{array}{c}\text { Partition } \\
\text { length } \\
(\mathbf{m})\end{array}$ & $\begin{array}{c}\text { Actual } \\
\text { calculation } \\
\mathbf{( N Z \$ )}\end{array}$ & $\begin{array}{c}\text { Loss } \\
\text { function } \\
\text { prediction } \\
(\mathbf{N Z \$ )}\end{array}$ \\
\hline 10 & 540 & 0.40 & 134.9 & 4,917 & 4,361 \\
9 & 540 & 0.67 & 114.6 & 18,589 & 19,421 \\
8 & 540 & 0.92 & 114.9 & 28,336 & 29,562 \\
7 & 540 & 1.13 & 133.6 & 38,239 & 34,280 \\
6 & 540 & 1.32 & 113.2 & 33,619 & 35,576 \\
5 & 540 & 1.47 & 147.2 & 44,164 & 35,904 \\
4 & 540 & 1.41 & 85.1 & 25,488 & 35,880 \\
\cline { 2 - 6 } & & & Total & 193,353 & 194,983 \\
\hline
\end{tabular}

The next step to be completed is to calculate an expected loss using the actual partition wall lengths. In order to do this, the actual length of partition walls and partition wall heights measured from the building plans are used along with the calculated inter-storey drifts, partition fragility functions and the mean repair costs for different damage states. Alternately, the drift and partition area can be directly used to calculate the actual expected loss due to partition damage using Figure 12 (i.e. the repair cost per square metre of partition vs. the interstorey drift). This is repeated for all floors throughout the building to obtain the total loss. The partition losses calculated by these two methods are compared in Table 6 .

As can be seen from Table 6, total partition losses for the building calculated from the two approaches differ by less than $1 \%$. The loss function slightly overestimates the expected partition loss because the actual length of partition walls in this building is marginally less than the average. However, significant difference between the two predictions can be observed in some floor level losses; this is mainly because the partition lengths in these floors distinctly differ from the mean partition ratio used in the loss function. For example, the $4^{\text {th }}$ floor loss varied by $29 \%$ due to the very small amount of partition on that floor compared to the average of the data collected. As expected, the cost of partition repair for the 96 Hereford Street building was more significant in the lower floors where the drift is larger.

To further confirm the applicability of the loss function, the method outlined above is applied for two more buildings damaged in the Canterbury earthquakes and demolished. These buildings are the previous Christchurch police station building and the 254 Montreal Street building.

The police station building was a 15 storey reinforced concrete structure, three levels of which were a podium about twice the plan area of the tower above. Based on the limited information of the foundation, the building was founded on sandy gravel for a depth of about seven metres, and below that a layer of about six metres of loose sand of medium density. The gravity loads and lateral forces were resisted by ductile reinforced concrete moment resisting frames. In the tower, the east-west and north-south frames consisted of four bays and three bays respectively [40]. A ductility factor of 2 is used for this structure. The natural period of the structure is estimated as $1.96 \mathrm{sec}$. The estimated inter-storey drift ratios vary between $1.64 \%$ and $0.33 \%$. Three stories are excluded from the calculations due to non-office application. The 254 Montreal Street building was a six storey building including a ground floor. The upper five stories are considered in the study and a ductility factor of 2 is assigned to the structure. The natural period of the structure is estimated as $0.7 \mathrm{sec}$. The estimated inter-storey drift ratios vary between $1 \%$ and $0.35 \%$.

The comparison between the actual calculation and the loss function prediction for the three case study buildings is shown in Table 7. Note that for consistency, all calculations shown in Table 7 are done without adjusting the rigid beam shear stiffness of the frames; that is why the loss for 96 Hereford Street is less than that shown in Table 6.

Table 7: Comparison between the predicted and the actual loss assessment for the case study buildings

\begin{tabular}{cccc}
\hline & \multicolumn{2}{c}{ Partition loss (NZ\$) } & Difference \\
\cline { 2 - 3 } & $\begin{array}{c}\text { Actual } \\
\text { calculation }\end{array}$ & $\begin{array}{c}\text { Loss } \\
\text { function }\end{array}$ & $(\%)$ \\
\hline 96 Hereford Street & 158,810 & 160,442 & 1.0 \\
254 Montreal Street & 63,939 & 64,010 & 0.1 \\
Police Station & 224,999 & 222,112 & 1.3 \\
\hline
\end{tabular}

The percentage difference between the two predictions is small enough $(<2 \%)$ for all three case study buildings. The average difference is $0.8 \%$. The police station building has the greatest cost due to the size of the building and higher expected drift levels; as a result there is a relatively larger difference between the loss function prediction and the actual calculation. The method is then repeated for the three buildings using different return period factors; i.e. for different seismic intensity levels. The expected losses due to damage of drywall partition per square metre of floor area obtained using the developed generic loss function and detailed loss analyses are presented in Table 8 . The percentage difference between the actual calculation using the measured partition lengths and the generic loss function prediction is also shown in Table 8 .

The police station building is expected to suffer a greater damage per floor area because it is subject to higher drift levels. The building at 254 Montreal Street undertakes small drift at a return period factor of 0.5 . Therefore, there is a low normalized cost and large percentage difference. The small percentage difference across the different buildings at different hazard levels indicates that the proposed partition wall loss function provides a tool for simple and quick estimation of partition loss in RC office buildings. It should be noted that the normalized loss is calculated with respect to the partition repair and replacement costs in Christchurch, New Zealand and may need to be adjusted for other countries. 
Table 8: Comparison of expected losses due to damage of drywall partition per square metre of floor area

\begin{tabular}{|c|c|c|c|c|}
\hline \multirow{2}{*}{$\begin{array}{c}\text { Return period factor } \\
\text { (Annual probability of exceedance) }\end{array}$} & \multirow{2}{*}{ Building } & \multicolumn{2}{|c|}{ Normalised partition loss (NZ\$) } & \multirow{2}{*}{ Difference $(\%)$} \\
\hline & & Actual calculation & Loss function & \\
\hline \multirow{3}{*}{0.5 ( 1 in 100 year $)$} & 96 Hereford Street & 11.9 & 12.0 & 0.9 \\
\hline & 254 Montreal Street & 2.2 & 2.0 & 8.8 \\
\hline & Police station & 14.8 & 14.4 & 2.8 \\
\hline \multirow{3}{*}{1 ( 1 in 500 year) } & 96 Hereford Street & 42.0 & 42.5 & 1.0 \\
\hline & 254 Montreal Street & 23.1 & 23.1 & 0.1 \\
\hline & Police station & 44.7 & 44.1 & 1.3 \\
\hline \multirow{3}{*}{1.3 ( 1 in 1000 year) } & 96 Hereford Street & 51.2 & 51.6 & 0.8 \\
\hline & 254 Montreal Street & 35.0 & 35.1 & 0.2 \\
\hline & Police station & 52.3 & 51.8 & 1.0 \\
\hline \multirow{3}{*}{1.8 ( 1 in 2500 year) } & 96 Hereford Street & 58.7 & 59.0 & 0.5 \\
\hline & 254 Montreal Street & 49.7 & 49.4 & 0.5 \\
\hline & Police station & 58.8 & 58.3 & 1.0 \\
\hline
\end{tabular}

\section{CONCLUSIONS}

Generalized loss functions for two important non-structural components (NSCs), namely suspended ceilings and drywall partitions, are developed herein. The existing methodologies for floor level loss functions are extended in combination with component distributions to develop generalized functions for $E D P$ vs. expected loss per square metre of floor area. The developed expected loss functions facilitate quick estimation of approximate seismic losses due to suspended ceilings and drywall partitions without requiring any specific information on the component amount/quantity and location within the building.

Using the drawings of a 725 rooms from 29 different RC office buildings in Christchurch CBD, a large data set of suspended ceilings and drywall partition sizes (in relation to the building floor area) was collected. In addition, builders and manufacturers were consulted to collect data on the repair and replacement costs of different levels of damage to these components. A series of MC simulations are carried out using the distributions of these collected data together with the fragility functions available in literature to develop generalised and normalized loss functions for these components. The collected data and the generated normalized loss functions suggest that the loss from suspended ceilings and partition damage in RC office buildings could be up to $5.5 \%$ and $3.4 \%$ of the total cost of the building, respectively. The usefulness of the developed loss functions are compared with the expected losses calculated using actual suspended ceiling component distributions from five floors of a case study building, and drywall partition from three case study buildings. The differences between the loss function predictions and the actual estimated losses are found to be negligibly small for both components across all the case study buildings subjected to different levels of seismic intensity.

The generic loss functions developed in this study provide a useful tool for fast prediction of the seismic losses contributed by suspended ceilings and drywall partitions without requiring any information on the distribution of these components. Such easy-to-use loss functions for all major components in a building are required to facilitate estimation of seismic loss of buildings for the future generation of performance based seismic design guidelines, which may use seismic loss as a key parameter for decision making

\section{ACKNOWLEDGEMENTS}

The authors are thankful to S. Pen, Z. Tang, E. Fraser and H. Merchant, former undergraduate students at University of
Canterbury, who collected and interpreted different parts of the data used in this paper. The only reason they are not listed as co-authors is that they could not be contacted to review the manuscript and provide their consent. The authors also appreciate the help from M. E. Koopaee during data collection and suggestions by Trevor Yeow on the analytical aspects of the study.

\section{REFERENCES}

1 Taghavi S and Miranda E (2003). "Response Assessment of Non-Structural Building Elements". PEER report 2003/05, College of Engineering, University of California Berkeley, USA.

2 Braga F, Manfredi V, Masi A, Salvatori A and Vona M (2011). "Performance of Non-Structural Elements in RC Buildings during the L'Aquila, 2009 Earthquake". Bulletin of Earthquake Engineering, 9(1): 307-324.

3 Bradley BA, Dhakal RP, Cubrinovski M, MacRae GA and Lee DS (2008). "Seismic Loss Estimation for Efficient Decision Making". Bulletin of the New Zealand Society for Earthquake Engineering, 42(2): 96-110.

4 Dhakal RP, Pourali A, Tasligedik S, Yeow T, Baird A, MacRae G, Pampanin S and Palermo A (2016). "Seismic Performance of Non-Structural Components and Contents in Buildings: An Overview of NZ Research". Earthquake Engineering and Engineering Vibration, (In-Press).

5 Freeman JR (1932). "Earthquake Damage and Earthquake Insurance: Studies of Rational Basis for Earthquake Insurance, Also Studies of Engineering Data for Earthquake Resisting Construction". $1^{\text {st }}$ edition, McGrawHill, NY, USA.

6 Scholl RE (1979). "Seismic Damage Assessment for HighRise Buildings: Annul Technical Report”. URS/John A. Blume \& Associates Inc., San Francisco, CA, USA.

7 Steinburgge KV (1982). "Earthquakes, Volcanoes, and Tsunamis: An Anatomy of Hazards". $1^{\text {st }}$ edition, Skandia America Group, NY, USA.

8 Singhal A and Kiremidjian AS (1996). "A Method for Earthquake Motion-Damage Relationships with Application to Reinforced Concrete Frames". Report No. 119, John A. Blume Earthquake Engineering Center, Stanford University, Stanford, CA, USA.

9 Kircher CA, Reitherman RK, Whitman R, and Arnold C (1997). "Estimation of Earthquake Losses to Buildings". Earthquake Spectra, 13(4): 703-720.

10 Moehle JP and Deirelein GG (2004). "A Framework Methodology for Performance-Based Earthquake 
Engineering". Proceedings of $13^{\text {th }}$ World Conference on Earthquake Engineering, Vancouver, BC, Canada, 1-6 August.

11 Yang TY, Moehle JP, Stodjadinivic B and Kiureghian AD (2006). "An Application of the PEER Performance-Based Earthquake Engineering Methodology". Proceedings of $8^{\text {th }}$ U.S. National Conference on Earthquake Engineering, San Francisco, CA, US.

12 Aslani H and Miranda E (2005). "Probabilistic Earthquake Loss Estimation and Loss Disaggregation in Buildings". Report No. 157, John A. Blume Earthquake Engineering Center, Stanford University, Stanford, CA, USA.

14 Solberg KM, Dhakal RP, Mander JB and Bradley BA (2008). "Computational and Rapid Expected Annual Loss Estimation Methodologies for Structures". Earthquake Engineering \& Structural Dynamics, 37(1): 81-101.

13 Mitrani-Reiser J (2007). "An Ounce of Prevention: Probabilistic Loss Estimation for Performance-Based Earthquake Engineering”. Ph.D. Dissertation, California Institute of Technology, California, USA.

15 Ramirez CM and Miranda E (2009). "Building-Specific Loss Estimation Methods \& Tools for Simplified Performance-Based Earthquake Engineering". Technical Report No. 171, John A. Blume Earthquake Engineering Center, Stanford University, Stanford, CA, USA.

16 FEMA (2012). "Next-Generation Methodology for Seismic Performance Assessment of Buildings". Report No. FEMA P-58, Applied Technology Council for the Federal Emergency Management Agency, Washington, D.C., USA.

17 Cutfield M, Ryan K and Ma Q (2015). "Comparative Life Cycle Analysis of Conventional and Base Isolated Buildings". Earthquake Spectra. (In-Press) http://dx.doi.org/10.1193/032414EQS040M.

18 Dhakal RP (2010). "First Step towards Loss Optimization Seismic Design (LOSD)". Proceedings of Asian Conference on Earthquake Engineering (ACEE), Bangkok, Thailand, 1-3 December.

19 Bradley BA (2008). "SLAT: Seismic Loss Assessment Tool, Version 1.12 User Manual". Department of Civil Engineering, University of Canterbury, Christchurch, New Zealand.

20 Farokhnia K and Porter K (2012). "Estimating the NonStructural Seismic Vulnerability of Building Categories". Proceedings of the $15^{\text {th }}$ World Conference on Earthquake Engineering, Lisbon, Portugal, 20-24 September.

21 Hamburger RO, Rojahn C, Heintz JA and Mahoney MG (2012). "FEMA P58: Next-Generation Building Seismic Performance Assessment Methodology". Proceedings of the $15^{\text {th }}$ World Conference on Earthquake Engineering, Lisbon, Portugal, 20-24 September.

22 NZS1170.5 (2004). "Structural Design Actions Part 5: Earthquake Actions". Standards New Zealand, Wellington, New Zealand.

23 Miranda E and Taghavi S (2009). "A Comprehensive Study of Floor Acceleration Demands in Multi-Story Buildings". Proceedings of ATC and SEI Conference on Improving the Seismic Performance of Existing Buildings and Other Structures, San Francisco, California, USA, 911 December.

24 Sullivan TJ, Calvi PM and Nascimbene R (2013). "Towards Improved Floor Spectra Estimates for Seismic Design”. Earthquakes and Structures, 4(1): 109-132.
25 Armstrong (2013). "Seismic Design Guide New Zealand Version, Suspended Ceiling Systems". Armstrong, Auckland, New Zealand.

26 Dhakal RP (2010). "Damage to Non-Structural Components and Contents in 2010 Darfield Earthquake". Bulletin of the New Zealand Society for Earthquake Engineering, 43(4): 404-411.

27 Dhakal RP, MacRae GA and Hogg K (2011). "Performance of Ceilings in the February 2011 Christchurch Earthquake". Bulletin of the New Zealand Society for Earthquake Engineering, 44(4): 377-387.

28 MacRae G, Hair J and Dhakal R (2011). "Ceiling Damage in the 2010 Canterbury Earthquake". Proceedings of Joint $8^{\text {th }}$ Center for Urban Earthquake Engineering (CUEE) and $8^{\text {th }}$ International Conference on Earthquake Engineering (ICEE) Conference, Tokyo, Japan, 7-8 March.

29 Paganotti G, MacRae G and Dhakal R (2011). "Development of Typical NZ Ceiling System Seismic Fragilities". Proceedings of the Ninth Pacific Conference on Earthquake Engineering: Building an EarthquakeResilient Society, Auckland, New Zealand, 14-16 April.

30 Dhakal RP, MacRae GA, Pourali A and Paganotti G (2016). "Seismic Fragility of Suspended Ceiling Systems Used in NZ Based on Component Tests". Bulletin of the New Zealand Society for Earthquake Engineering: Special Issue on the Seismic Performance of Non-Structural Elements in Buildings, 49(1): 45-64.

31 IFI 114: American Standard Blind Rivet. "Break Mandrel Rivets, Industrial Fasteners Institute". USA.

32 Badillo-Almaraz H, Whittaker AS, Reinhorn AM (2007). "Seismic Fragility of Suspended Ceiling Systems". Earthquake Spectra, 23(1): 21-40.

33 USG Australia (2012). "Generic Seismic Design for USG DONN Exposed Grid Suspended Ceilings". USG, Auckland, New Zealand.

34 Giddens C (2013). "Rawlinsons New Zealand Construction Handbook". Rawlinsons Media Limited, Auckland, New Zealand.

35 Tasligedik AS, Pampanin S and Palermo A (2014). "Low Damage Seismic Solutions for Non-Structural Drywall Partitions". Bulletin of Earthquake Engineering, 13(4): 1029-1050.

36 Tasligedik AS, Pampanin S and Palermo A (2012). "Damage States and Cyclic Behaviour of Drywalls Infilled Within RC Frames". Bulletin of the New Zealand Society for Earthquake Engineering, 45(2): 84-94.

37 Lee TH, Kato M, Matsumiya T, Suita K and Nakashima M (2007). "Seismic Performance Evaluation of NonStructural Components: Drywall Partitions". Earthquake Engineering \& Structural Dynamics, 36(3): 367-382.

38 Porter KA and Kiremidjian AS (2001). “Assembly-Based Vulnerability of Buildings and Its Uses in Seismic Performance Evaluation and Risk Management DecisionMaking”. Report No. 309, John A. Blume Earthquake Engineering Center, Stanford University, Stanford, CA, USA.

39 Rihal SS (1982). "Behaviour of Non-Structural Building Partitions during Earthquakes". Proceedings of the Seventh Symposium on Earthquake Engineering, Roorkee, India, 10-12 November.

40 Canterbury Earthquakes Royal Commission (2012). "Final Report Volume 2: The Performance of Christchurch CBD Buildings". Christchurch, New Zealand. 